\title{
Epidemiological aspects of the risk factors needed to acquire the tapeworm/cysticercosis complex in Mexico
}

\author{
Juan J. Gómez-Piña ${ }^{1,2 *}$ and Agnès Fleury ${ }^{2,3}$ \\ ${ }^{1}$ Department of Neurology and Psychiatry, Instituto Nacional de Ciencias Médicas y Nutrición Salvador Zubirán; ${ }^{2}$ Neuroinflammation Unit, Instituto \\ de Investigaciones Biomédicas - UNAM/Instituto Nacional de Neurología y Neurocirugía; ${ }^{3}$ Neurocysticercosis consultation, Instituto Nacional de \\ Neurología y Neurocirugía. Mexico City, Mexico
}

\begin{abstract}
Introduction: Cysticercosis is still an endemic disease in Mexico, because our country has the main unhealthy conditions to acquire this microorganism, such as the lack of drainage, water, sanitation, and the coexistence with pigs of rustic breeding. Objective: The objective of the study was to evaluate the current prevalence (2015 INEGI database) of risk factors necessary to develop tapeworm/cysticercosis complex and to compare them with the 2010 situation. Materials and methods: The last INEGI database were consulted and compared with the 2010 data, these dates were obtained per state to evaluate the risk factors of states and townships. Results: The current distribution of the 32 Mexico's states, showed an improvement of water, toilet, drainage, and pigs in housing, compared to the previous data from 2010 database. Conclusions: There was an improvement in Mexico's states, lowering risk factors to acquire tapeworm/cysticercosis complex, although unhealthy conditions still remain in 20 of 32 states of Mexico.
\end{abstract}

Key words: Cysticercosis. Unhealthy. Mexico. Prevention. Risk factor.

\section{Aspectos epidemiológicos de los factores de riesgo necesarios para adquirir el complejo teniasis/cisticercosis en México}

\section{Resumen}

Introducción: La cisticercosis sigue siendo una enfermedad endémica en México porque nuestro país cumple con las principales condiciones insalubres para adquirir este microorganismo, como por ejemplo, la falta de drenaje, agua, instalaciones sanitarias y la convivencia con cerdos de cría rústica. Objetivo: Evaluar la prevalencia actual (base de datos INEGI 2015) de los factores de riesgo necesarios para desarrollar el complejo teniasis/cisticercosis y compararlos con la situación de 2010. Métodos: Se consultó la última base de datos INEGI y se comparó con los datos de 2010. Estas fechas se obtuvieron por estado para evaluar los factores de riesgo de los estados y municipios. Resultados: La distribución actual de los 32 estados de México mostró una mejora del agua, el inodoro, el drenaje y los cerdos en las viviendas, en comparación con los datos anteriores de la base de datos de 2010. Conclusiones: Hubo una mejora en los estados de México, disminuyendo los factores de riesgo para adquirir el complejo de teniasis/cisticercosis, aunque aún se mantienen condiciones insalubres en 20 de los 32 estados de México.

Palabras clave: Cistercosis. Insalubre. México. Prevención. Factor de riesgo.

${ }^{*}$ Correspondence:

Juan J. Gómez-Piña

E-mail: drjgomezp@gmail.com
Available online: $30-11-2020$ Rev Mex Neuroci. 2020;21(6):222-227 www.revmexneurociencia.com 1665-5044/ @ 2020 Academia Mexicana de Neurología A.C. Published by Permanyer. This is an open access article under the CC BY-NC-ND license (http://creativecommons.org/licenses/by-nc-nd/4.0/). 


\section{Introduction}

Neurocysticercosis is the most frequent central nervous system (CNS) parasitic disease, being human the only definitive host, while pig is the main intermediate. Taenia solium causes taeniasis, when adult parasite is lodged in the small bowel, and cysticercosis, when larval form is lodged in CNS and skeletal muscle.

Neurocysticercosis is still diagnosed frequently in Mexican patients; the Instituto Nacional de Neurología y Neurocirugía, attended 429 new cases from 2000 to 2014, which means 28-29 patients per year in the hospital ${ }^{1-3}$.

According to the 2005 Sistema Nacional de Vigilancia Epidemiológica (SUIVE), the national incidence of taeniasis is up to $0.37 \% \%^{4}$. Studies made in Mexico suggest that $8-13 \%$ of pigs are infected with cysticercosis, predominately in Puebla and Guerrero ${ }^{5}$.

Main risk factors to acquire this infection in Mexico are lack of water, drainage, toilet, and pigs in housing, which are prevalent in most of Mexico's communities; however, lack of water and/or low quality of it are most important factors to acquire tapeworm/cysticercosis complex in our country, feature which keeps in marginal and rural areas ${ }^{6}$.

According to the last GLAAS report (UN-Water Global Analysis and Assessment of Sanitation and Drinking-Water) is needed to increase public and free access to quality water, increasing the use of toilet and population's hygiene in Mexico, especially in marginal, rural or farer areas, where there are susceptible population?

Previously, we applied the same methodology to 2010 Instituto Nacional de Estadística y Geografía (INEGI) database, considering lack of water, sanitary, drainage, and pigs in housing, obtaining 21 affected states corresponding to the 100 first townships affected. Although there was significant correlation between all national townships and Human Development Index (HDI), no significant correlation between just 100 townships and $\mathrm{HDI}^{8}$.

\section{Materials and methods}

We consulted the population and housing 2015 INEGI census, and agricultural INEGI census, to obtain number of inhabitants, houses with lack of water, houses without drainage, houses without toilet, and number of houses with pigs in housing. These data were considered during the period of 2010-2015, considering as an inclusion criteria, states, and townships with high number of houses with lack of water, houses without drainage, houses without toilet, and houses with pigs in housing. We selected states and townships with highest number or percentage of houses meeting these criteria, to be compared with HDI, hypothesizing the highest risk factors the lower HDI. Hence, states and townships were classified to obtain a percentage per township and state, these data were ordered from higher to lower frequency to get risky areas according to Pearson correlation. Moreover, results were graphic in a national map to check the most affected areas in 2015, and compare with 2010 INEGI previous results.

\section{Results}

The main townships which meet high risk factors and a low HDI were located in the first quartile of all Mexican townships. This township belongs to all Mexicans states, but just the first 100 townships belonged to 20 of 32 states of Mexico (Table 1), with 2,360,752 (14,074220,000 , IC $95 \%$ ) of risked habitants, representing a $1.968 \%$ of national population, and $3.094 \%$ of risked states population.

In the other hand, we found that population grown an 8.064\% ( $n=8,920,678)$ between 2010 and 2015 according to INEGI database, representing a $0.154 \%$ $(n=13,738)$ grown of risked population, compared to 2010 analysis (Fig. 1) ${ }^{8}$. Moreover, the HDI of Mexican states were from 0.667 to 0.79 with a medium HDI of 0.73 (Fig. 2). The state with the higher HDI was Nuevo Leon with 0.79 , and the lower $\mathrm{HDI}$ was Chiapas with 0.667 .

Finally, we compared the HDI with risk factors, hypothesized that the higher HDI the lower risk factors, obtaining a significant Pearson correlation with $p=0.01$ $(R=0.529)$, concluding that the most affected state was Guerrero with $7.55 \%$ of risked population, and the less affected state was Puebla, with $0.04 \%$ of risked population (Fig. 3).

\section{Discussion}

According to our results, the risk factors keeps in the most of areas in Mexico, unfortunately between 2010 and 2015 there were and increasing of $0.154 \%$ of risked population, corresponding to 978,834 habitants. These data suggest that risk factors are still remaining in Mexico, but some areas have shown an improvement while others did not. The distribution of these 
Table 1. Results of main risked factor's states, HDI, and population in Mexican analysis

\begin{tabular}{|c|c|c|c|c|}
\hline State & Municipal population & State population & Percentage of risk population & HDI \\
\hline Oaxaca & 4365 & $3,967,889$ & 0.110 & 0.681 \\
\hline Puebla & 3084 & $6,168,883$ & 0.049 & 0.717 \\
\hline Baja California Sur & 1496 & 712,029 & 0.210 & 0.776 \\
\hline Hidalgo & 3429 & $2,858,359$ & 0.119 & 0.723 \\
\hline Michoacán & 46,762 & $4,584,471$ & 1.020 & 0.7 \\
\hline Nayarit & 6731 & $1,181,050$ & 0.569 & 0.733 \\
\hline Querétaro & 18,954 & $2,038,372$ & 0.929 & 0.76 \\
\hline Chiapas & 35,482 & $5,217,908$ & 0.680 & 0.667 \\
\hline Aguascalientes & 9583 & $1,312,544$ & 0.730 & 0.76 \\
\hline Chihuahua & 19,207 & $3,556,574$ & 0.540 & 0.734 \\
\hline Estado de México & 100,366 & $16,187,608$ & 0.620 & 0.745 \\
\hline Zacatecas & 17,688 & $1,579,209$ & 1.120 & 0.72 \\
\hline Colima & 18,428 & 711,235 & 2.590 & 0.763 \\
\hline Veracruz & 930,019 & $8,112,505$ & 0.370 & 0.713 \\
\hline Campeche & 17,634 & 899,931 & 1.959 & 0.749 \\
\hline Tamaulipas & 84,322 & $3,441,698$ & 2.450 & 0.758 \\
\hline Nuevo Leon & 160,755 & $5,119,504$ & 3.140 & 0.79 \\
\hline Tabasco & 453,157 & $2,395,272$ & 4.306 & 0.742 \\
\hline San Luis Potosi & 162,528 & $2,717,820$ & 5.980 & 0.726 \\
\hline Guerrero & 266,762 & $3,533,251$ & 7.550 & 0.679 \\
\hline Total & $2,360,752$ & $76,296,112$ & 1.752 & 0.7318 \\
\hline \multicolumn{4}{|c|}{ Percentage of risk factors according to national population 2015} & 1.968 \\
\hline \multicolumn{4}{|c|}{ Increased of risked population from 2010 to 2015} & 0.154 \\
\hline \multicolumn{4}{|c|}{ Percentage of risked population according to risked states } & 3.094 \\
\hline \multicolumn{4}{|l|}{ Medium HDI } & 0.731 \\
\hline \multicolumn{4}{|c|}{2015 population (INEGI) } & $119,938,473$ \\
\hline \multicolumn{4}{|c|}{ Increased of population in 5 years } & 8.064 \\
\hline
\end{tabular}

data (2005-2015) shows us that risk factors to acquire tapeworm/cysticercosis complex are common and prevalent in the most of states of Mexico, which represents the need to implement preventive measures in these states to reduce the incidence of this infection in our country.

Mohit et al. explored Nottinghamshire County Council's (NCC's) risk factors, including patients with NCC who used water from unsafe drinking sources, or whom disposed garbage close to water source, obtaining that there were more slaughter houses and pigs around the houses of NCC patients than the control group 9 .

We suggest preventive measures as improving the health and hygiene of these areas, as well as implementing vaccination in pigs in the areas of greatest impact to eradicate this epidemic, taking into consideration that the main risky states are the main states with low population affiliated to health system (Fig. 4). 


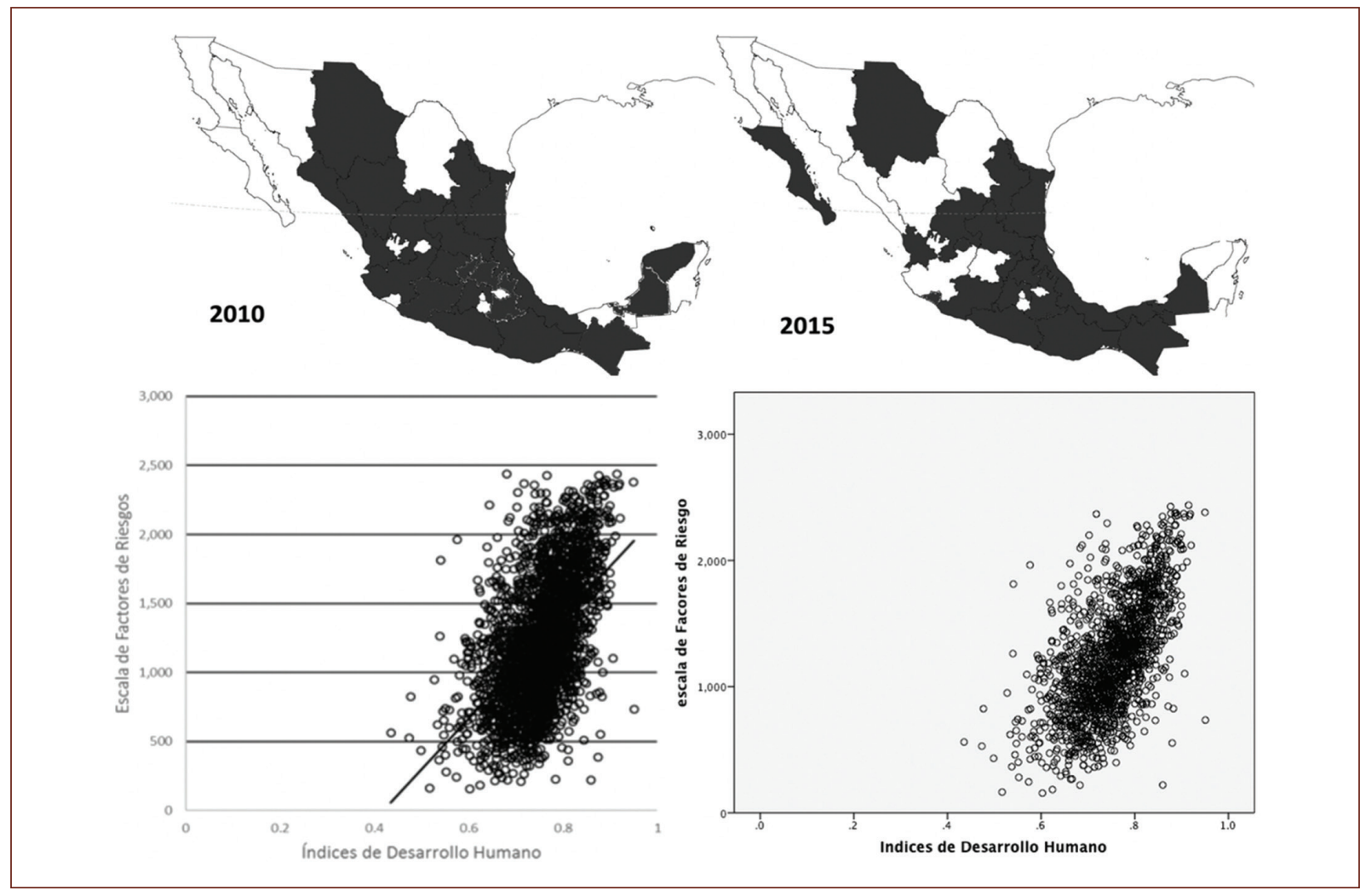

Figure 1. Comparison between 2010 and 2015 analysis, pictured the most affected states in Mexico, as well as transition in dispersion graphics of affected township areas.

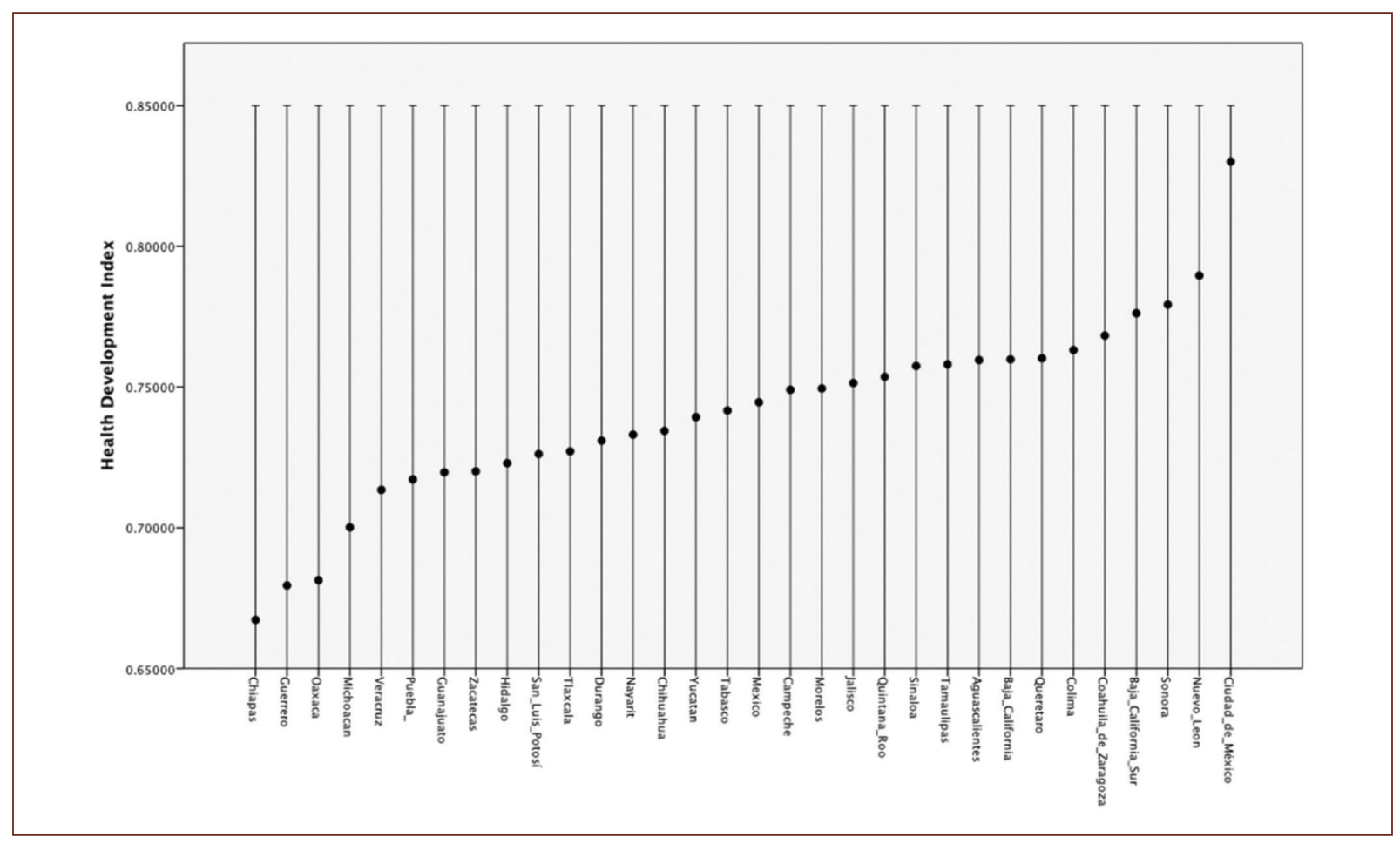

Figure 2. National Human Development Index (HDI) per states and ascending form (PNUD). 


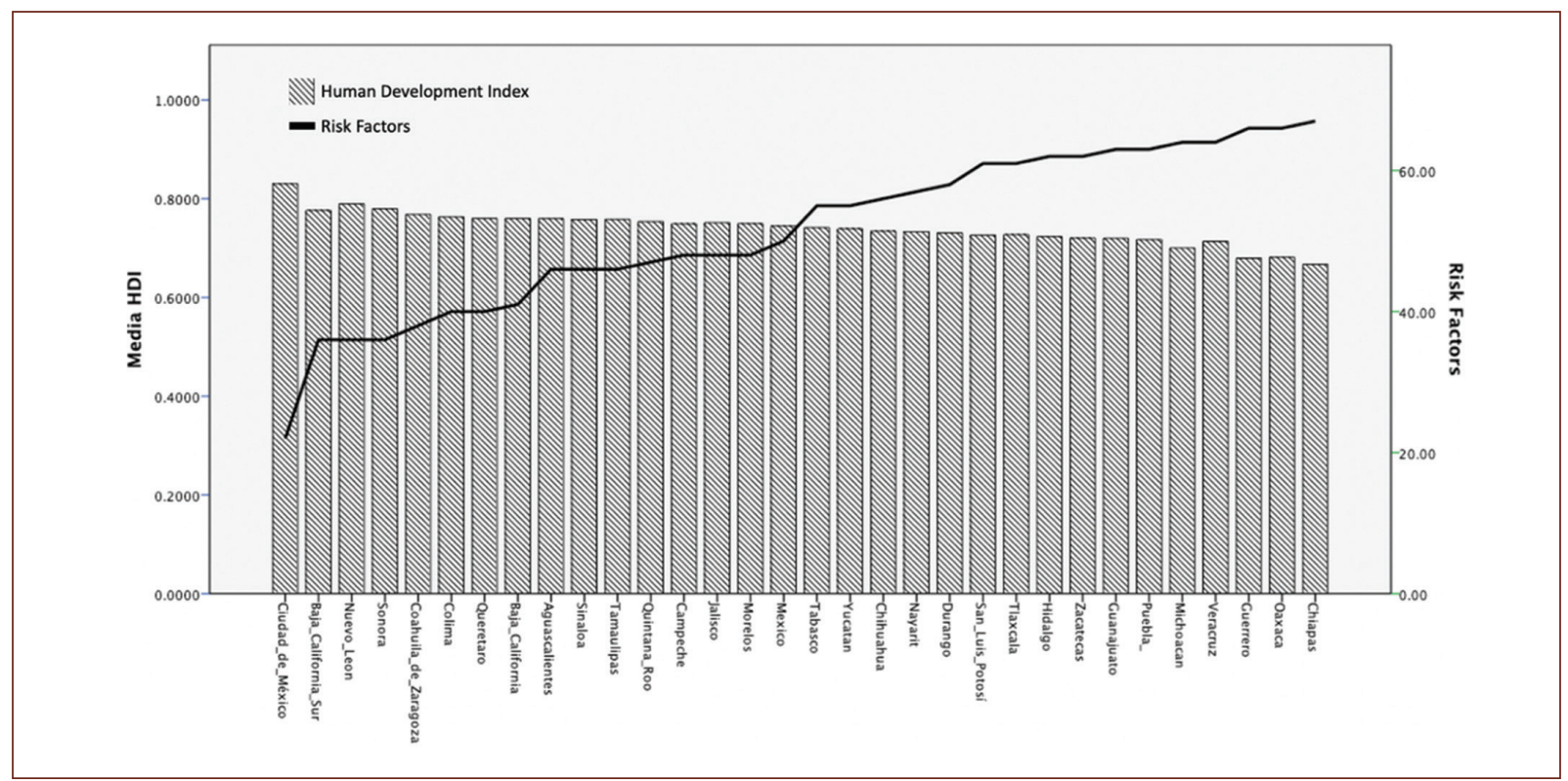

Figure 3. Association between HDI and risk factors, showing significant relation between high risk factors with low HDI.

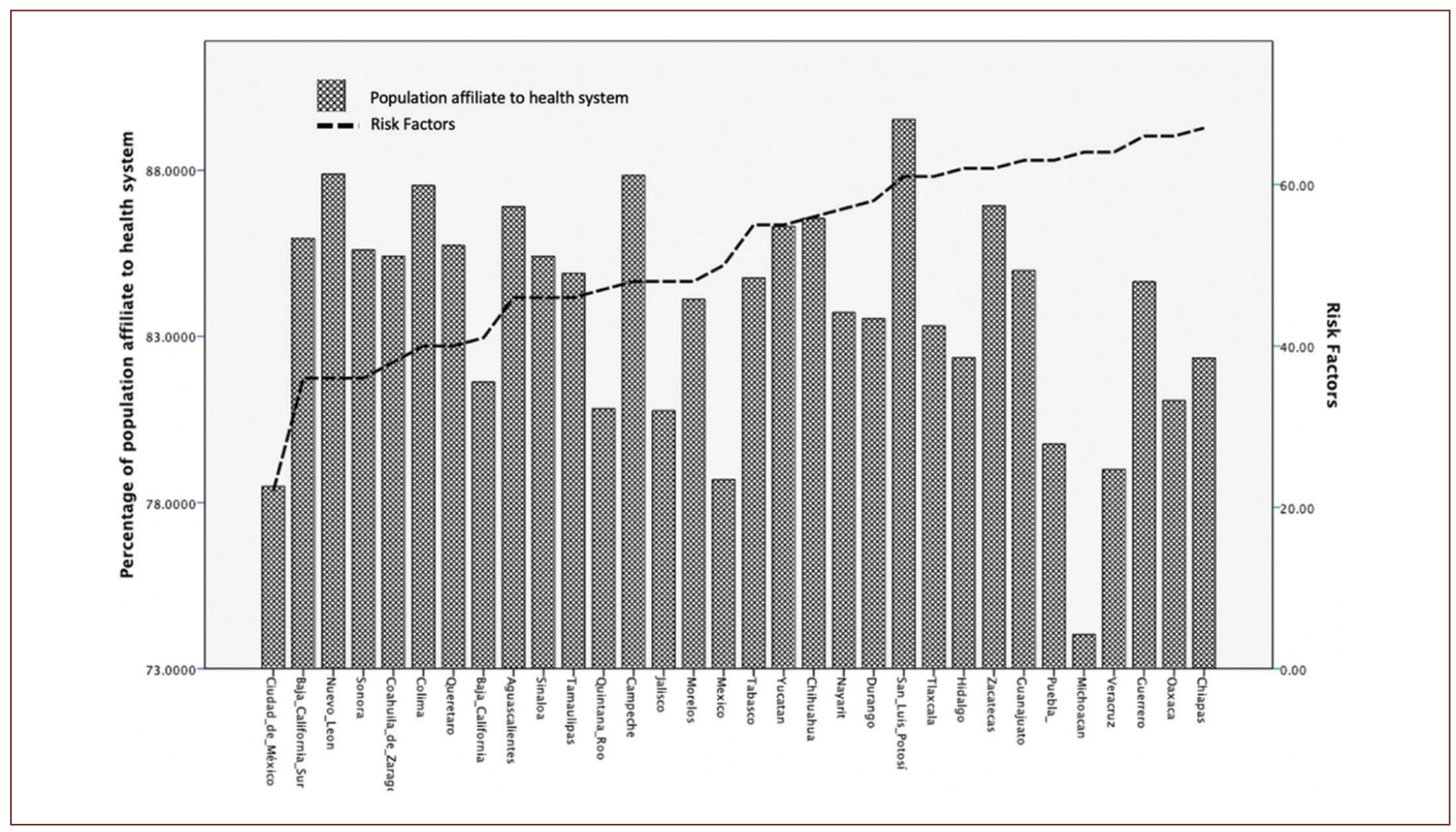

Figure 4. Relationship between population affiliated to health system and risk factors according to our methodology, with no direct relations between the higher risk factor the higher population affiliated to health systems, $p=0.000$, Regression, $\mathrm{R}=0.159$.

\section{Conclusions}

Comparing the 2010 and 2015 results according to our methodology, we obtained an improvement in risk factors, with a low increasing of affected population, and a maintenance of $\mathrm{HDI}$ in the past 5 years. There were 20 of 32 affected states, compared to the previous analysis from 2010, with 21 of 32 affected states. Although there are less affected states, the population in them 
keeps risk factors and unhealthy conditions, which are necessary to acquire tapeworm/cysticercosis complex.

\section{Funding}

None.

\section{Conflicts of interest}

None.

\section{Ethical disclosures}

Protection of human and animal subjects. The authors declare that no experiments were performed on humans or animals for this study.

Confidentiality of data. The authors declare that they have followed the protocols of their work center on the publication of patient data.

Right to privacy and informed consent. The authors have obtained the written informed consent of the patients or subjects mentioned in the article. The corresponding author is in possession of this document.

\section{References}

1. Del Brutto $\mathrm{OH}$, Sotelo J. Neurocysticercosis: an update. Rev Infect Dis. 1988;10:1075-87.

2. Flisser A. Neurocysticercosis in Mexico. Parasitol Today. 1988;4:131-7.

3. Marcin Sierra M, Arroyo M, Cadena Torres M, Ramírez Cruz N, García Hernández F, Taboada D, et al. Extraparenchymal neurocysticercosis: demographic, clinicoradiological, and inflammatory features. PLoS Negl Trop Dis. 2017; 11:e0005646.

4. Sistema Único de Información. Sistema Nacional de Vigilancia Epidemiológica Semana 42. Aspectos Relevantes Sobre el Binomio Teniasis/ Cisticercosis. México: Sistema Único de Información; 2007.

5. Sciutto CE, Martínez JJ, Villalobos NM, Hernández M, José MV, Beltrán C, et al. Limitations of current diagnostic procedures for the diagnosis of Taenia solium cysticercosis in rural pigs. Vet Parasitol. 1998;79: 229-313.

6. Morales J, Martínez JJ, Rosetti M, Fleury A, Maza V, Hernandez M, et al. Spatial distribution of Taenia solium porcine cysticercosis within a rural area of Mexico. Trop Dis. 2008;2:e284.

7. WHO/UNICEF. Investing in Water and Sanitation: Increasing Access, Reducing Inequalities, UN-Water Global Analysis and Assessment of Sanitation and Drinking-Water (GLAAS) 2014-Report. Geneva: World Health Organization; 2014

8. Gómez-Piña JJ, Fleury A. Situación actual de los factores de riesgo para el complejo teniosis/cisticercosis en México. Rev Mex Neuroci. 2017;18:34-48.

9. Girotra M, Gera C, Abraham RR, Kaur P, Gauba R, Singh Y, et al. Risk factors for neurocysticercosis: a study from Northwest India. CHRISMED $\mathrm{J}$ Health Res. 2014;1:21-4. 